Bulletin of the Seismological Society of America. Vol. 58, No. 3, pp. 891-916. June, 1968

\title{
VIBRATION AND SOIL-STRUCTURE INTERACTION TESTS OF A NINE-STORY REINFORCED CONCRETE BUII.DING
}

\author{
By Paul C. Jennings and Julio H. Kurotwa
}

\begin{abstract}
The Millikan Library Building, a nine-story reinforced concrete shear-wall structure at the California Institute of Technology, was tested dynamically by means of two eccentric mass vibration generators located on the ninth floor. The response levels ranged up to a maximum acceleration of 0:02 $\mathrm{g}$. The natural periods of vibration, the mode shapes and the energy dissipation were measured for the first and second E-W translational modes, the N-S fundamental mode and the first torsional mode. Soil-structure interaction was investigated by measuring foundation motion and nearby soil surface movements during resonent vibrations in the N-S and E-W fundamental modes. Other tests included "man-excited" vibrations at low stress levels and a measurement of resonance of an air handling unit on the roof, which was found to magnify the roof response by a factor of 8.5.

The measured fundamental periods were short compared to typical framed structures of this height, $0.50 \mathrm{sec}$ in the N-S direction, 0.66 in the E-W direction and 0.46 in torsion. These values increased roughly 3 per cent over the range of testing. The energy dissipation as measured by a viscous damping factor, varied between 0.70 and 2.00 per cent of critical. This large variation over the testing range indicates that fests at higher stresses are needed to determine the energy dissipation expected during the response to strong earthquake motions.

The soil-structure interaction measurements showed that the building responded very nearly as if fixed at the foundation; rocking contributed less than 1 per cent to the total roof motions of the structure and foundation translation about 2 per cent. Although negligible as far as the building motion is concerned, the results demonstrate the possibility of performing full-scale soil-structure interaction experiments.
\end{abstract}

\section{INTRODUCTION}

Full-scale vibration tests using large shaking machines have proved to be one of the most effective methods for determining the dynamic characteristics of structures needed for understanding the effects of strong earthquake motions. With these vibration generators it is possible to determine experimentally the most important periods and mode shapes of many actual structures, and to measure their energy dissipation properties. Also, as reported below, these machines can be used to perform full-scale experiments on the phenomenon of soil-structure interaction. The principal limitation of the vibration generators is that the testing range is generally limited to small vibrations.

An important advance in this field of dynamic testing was the development in 1961 of a vibration generating system with precise speed control and the capability 
of phase control among separate units (Hudson, 1962). These vibration generators have been used to test a variety of actual structures, including dams (Keightley, 1963,1964 ); a reservoir intake tower (Keightley et al, 1961); an atomic reactor (Matthiesen and Smith, 1966); a variety of buildings (Nielsen, 1964; Bouwkamp and Blohm, 1966; Englekirk and Matthiesen, 1967; Hanson, 1965a); and special structures (Hanson, 1965b). In Japan also, a program of full-scale vibration tests has been carried out using similar equipment (Kawasumi and Kanai, 1956; Hisada and Nakagawa, 1956; Takeuchi, 1960; Nakagawa, 1960).

The main purpose of the tests reported here was twofold. First, to study the dynamic characteristics of the Millikan Library Building, and second to study the amount of interaction between the structure and the surrounding soil. These results will be useful in analytical studies being made of the structure and in the interpretation of future records from the strong-motion accelerographs which are installed in the building.

In this test it was possible to excite the structure in the fundamental modes in the N-S and E-W directions, and in torsion. It was possible also to study the second E-W mode to a limited extent but other modes were out of the range of the equipment. Soil-structure interaction data were taken for the two fundamental modes in translation. A more detailed discussion of test results and procedures, and additional data not reported here are available in a recent report (Kuroiwa, 1967).

Building Data. The structure tested was the Robert A. Millikan Library Building located on the campus of the California Institute of Technology. Built during 19661967 , it is a nine-story reinforced concrete building with a basement. The overall dimensions of the building are shown in Figures $1 \mathrm{a}, 1 \mathrm{~b}$ and 1c, and a general view in Figure 1d. The floor system consists of 9 in. slabs of lightweight concrete reinforced in two directions and supported by reinforced concrete beams. The north side and south side facades, installed during preliminary testing, are precast window wall panels weighing 11 tons each, connected to the main structure with steel angle clips. The lateral resistance in the N-S direction is supplied primarily by the two end walls; and in the E-W direction by the central core. The masses in kips at the time the tests were performed were assumed to be lumped at each floor level and were estimated to be: $M_{10}$ (roof) $=2,600 ; M_{9}-M_{3}=1950 ; M_{2}=2433$; and $M_{1}=2280$. The mass of the roof includes the mechanical equipment, most of which is used to heat and cool the building.

Instrumentation and Test Procedures. The vibration tests consist basically of determining the steady-state response of the building to a sinusoidal exciting force produced by the eccentric masses of the vibration generators. The building was excited with two generators, installed on the ninth floor at locations A and B of Figure 1b. Each unit generates a unidirectional, sinusoidal force which can be varied in magnitude and direction. The maximum force level is about $5000 \mathrm{lbs}$, and the maximum rotational speed is about 10 cycles per second. Particulars of the vibrators, including operating instructions for the machines, are available (Hudson, 1962).

The response of the building and nearby ground at selected locations was recorded with a 6-channel accelerometer-amplifier-recorder system. Data were recorded only after transient structural vibrations had died out; this occurred quickly except near resonance where 20-30 cycles of response were often necessary. By taking a series of 


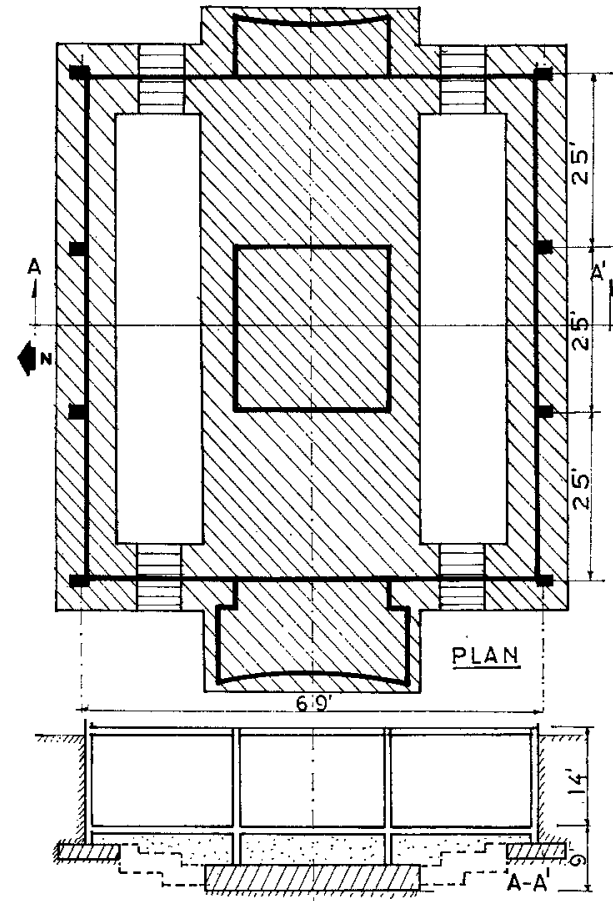

A

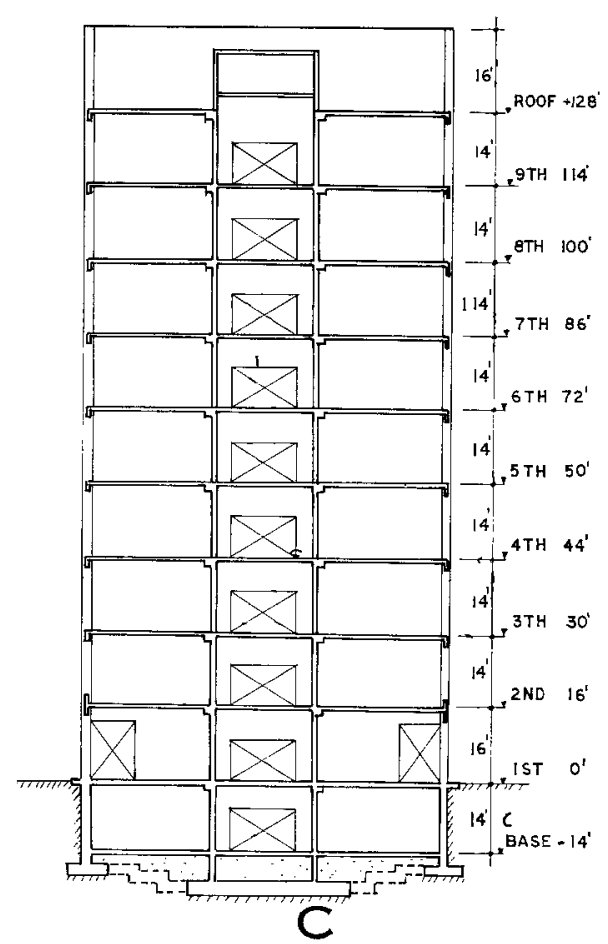

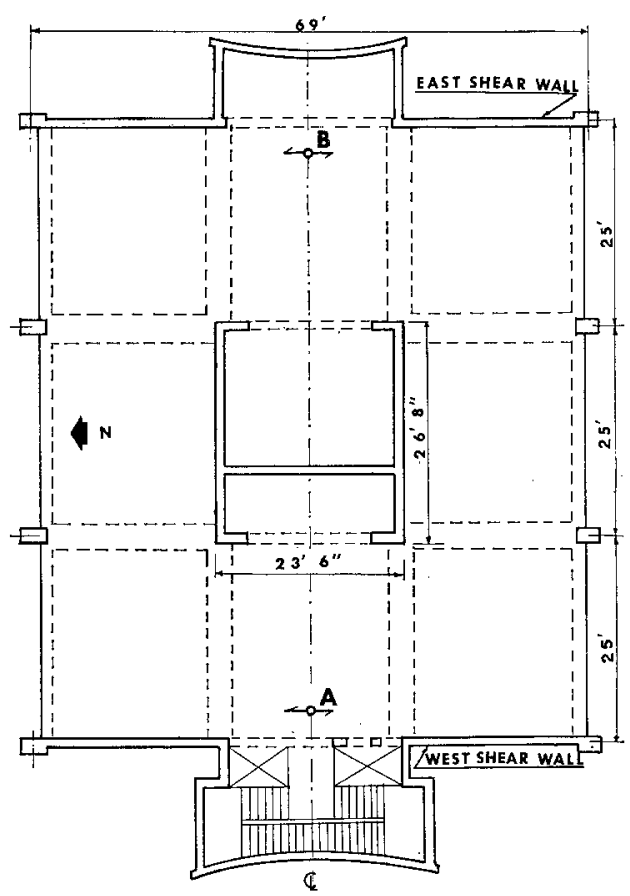

B

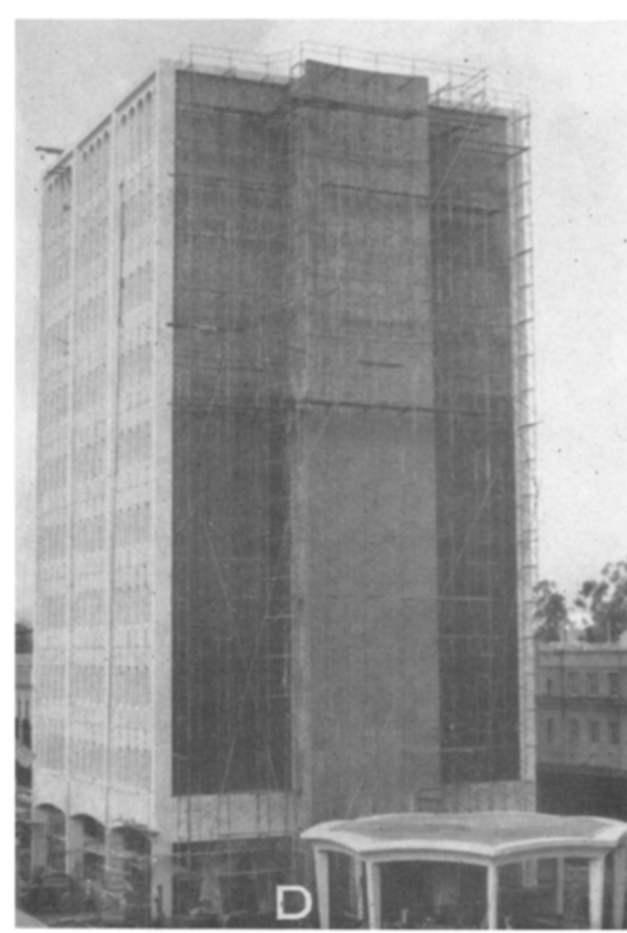

FIG. 1. Millikan Library Building: (a) Foundation plan and a N-S section; (b) Typical floor plan showing location of the vibration generators; (c) A N-S section; (d) General view of the building looking northwest. 
acceleration data, the steady-state response of the building was obtained, the usual order being an increase of the excitation frequency in appropriate steps through resonance of the structure. For each frequency the magnitude of the recorded sinusoidal acceleration gives a point on a steady-state response curve, and a series of such points for constant eccentric mass in the shaking machines generates an acceleration response curve. In a typical test, after data for a curve had been taken, the vibration generators were stopped, additional eccentric masses added, and another set of data taken. This process was continued until the limits of the machines were reached.

For the soil-structure interaction tests the building was maintained at resonance in the desired mode while soil and foundation accelerations were recorded.

Analysis of the Data. The natural periods of vibration were determined from the acceleration response curves. Because the damping was found to be consistently less than 2 per cent, the resonant frequency found from an acceleration response curve differs by less than 0.1 per cent from that found from a displacement response curve, so a distinction between these two frequencies was not made.

The damping values associated with the vibration levels were calculated by the three methods given below. These values are determined by the geometry of the frequency response curves for a particular mode of response and give an estimate of the energy dissipation ability of the structure when it is vibrating in that mode. The methods used are derived from analyses of idealized linear structures, and have been found to give slightly different results when applied to actual structural response.

Method I. This method uses the well-known result that the amount of viscous damping in a linear, single-degree of freedom system can be found from the width of the response curve at $\sqrt{\mathrm{z} / \mathrm{z}}$ of the peak response.

Method II. If the natural frequencies of a linear structure are separated sufficiently for a pure mode to be excited by a sinusoidal force at a single level, the damping can be determined from the exciting force, the mode shape and the response magnitude (Nielsen, 1964).

Method III. For a lightly damped linear oscillator, the damping can be found from the maximum and subsequent minimum response acceleration (Hudson, 1962).

\section{Building Vibration Test Results}

Preliminary Tests. For dynamic tests of large structures it is necessary to assume that vibrations measured at selected points are the same as those occurring in adjacent portions of the building. In the Millikan Library tests one accelerometer was placed on every other floor, and it was assumed that the acceleration recorded at this point would be representative of the entire floor. In order to check the validity of this assumption a preliminary test was made in which six accelerometers were placed on the ninth floor, located as shown in Figure 2, five measuring vibration in the N-S direction, and one in the E-W direction. The two vibration generators were synchronized to produce equal forces acting in phase in the N-S direction. Another reason for performing this test was to verify the assumption that every floor system acted as a rigid diaphragm, distributing shear forces to the vertical elements in proportion to their rigidities.

Figure 2 shows part of the results of this test and shows that points in the central and eastern parts of the ninth floor (locations 3,6,2 and 5 in Figure 2) all had a measured North-South acceleration of $(5.83 \pm .03) 10^{-4} \mathrm{~g}$. East-West motion of the 


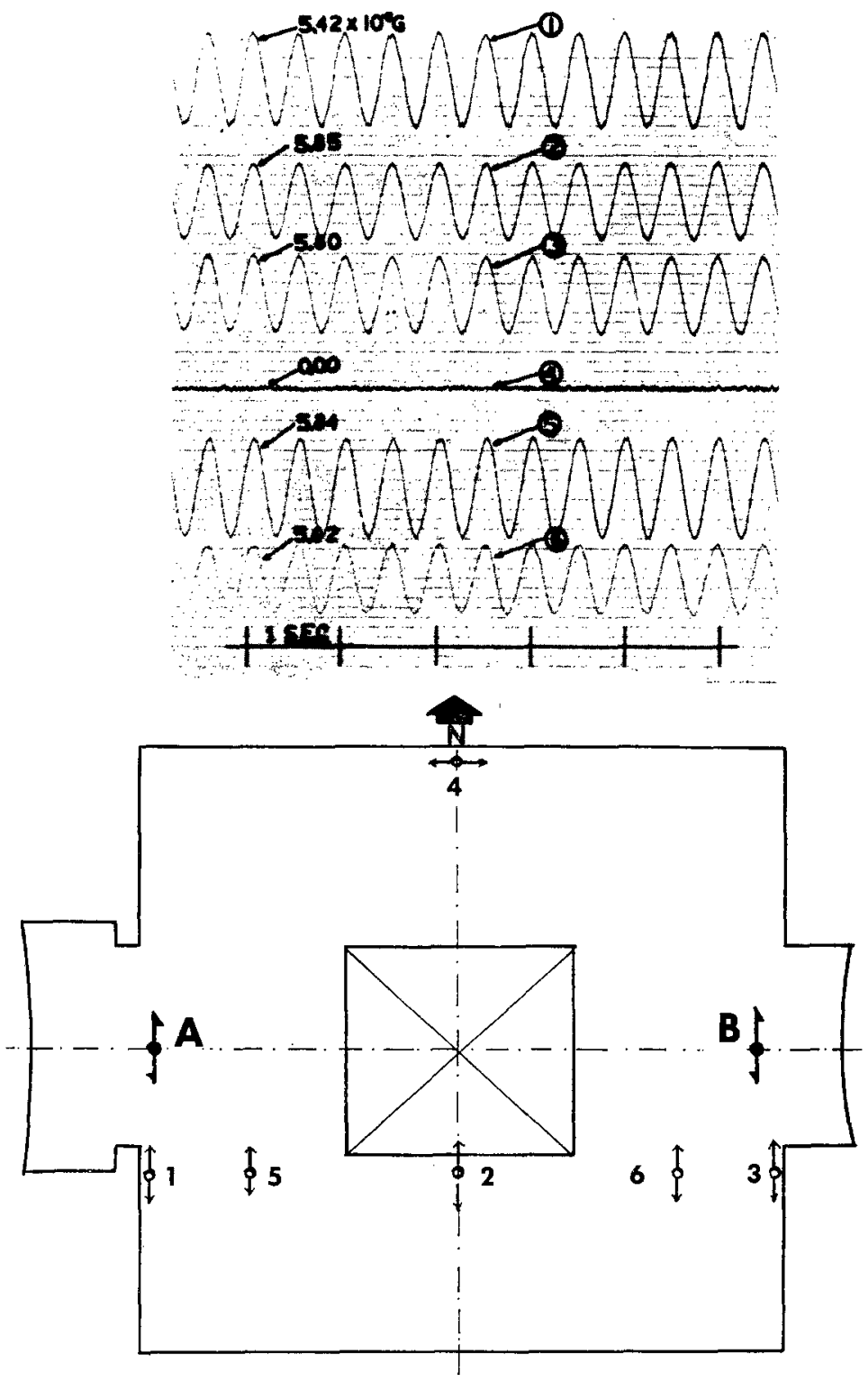

FIG. 2. Ninth floor response in the first mode, N-S direction. Above: sample recorded during the test; below: location of the accelerometers.

floor was undetectable during the test (location 4). Near the west shear-wall (location 1 ) the acceleration measured was $5.42 \times 10^{-4} \mathrm{~g}$. This smaller movement may be a result of experimental error, but the authors judged that the measured accelerations on the tests are generally accurate to at least two significant figures, so the lower value of the acceleration near the west shear-wall is probably real, perhaps attributable to some deformation of the floor system by the action of the west shearwall.

From the test shown in Figure 2 it was concluded that the first mode in the N-S 
direction is a pure translation mode, with no component in the E-W direction. Further, it was concluded that the acceleration of each floor in this mode could be represented sufficiently well by a single reading taken near the center of the building, away from the shear walls. A similar test performed in the E-W direction confirmed that these conclusions hold also for vibration in the $\mathbf{E}-\mathrm{W}$ fundamental mode.

The center of torsion of the building was determined by exciting the building with the vibrators oriented in the N-S direction, $180^{\circ}$ out of phase. Four accelerometers were placed on the ninth floor at the center of each side of the building and two were placed on the eighth floor close to the center of the east and west shear walls. From this test it was found that the center of torsion on the ninth floor was on the E-W centerline $2^{\prime} 6^{\prime \prime}$ west of the geometrical center of the building, and further, that this location did not vary with response amplitude. The eighth floor measurement showed that the westerly deviation of the torsional center tends to decrease toward ground level as expected from the geometry of the building.

Translational Mode in the N-S Direction. Two test periods, one week apart, were used to study the $\mathrm{N}-\mathrm{S}$ fundamental mode. During the intervening time, some plaster, ductwork and ceiling materials were added to the building. Guided by preliminary tests, one accelerometer was placed on each of the 10 (roof), 8th, 6th, 4th, 2nd and 1st floors for the first three tests. For the next three tests, the first floor accelerometer was moved to the basement; the others were not moved. Each accelerometer was placed one foot north of the elevator core and $2^{\prime} 6^{\prime \prime}$ west of the N-S centerline. Any errors resulting from the eccentricity of the accelerometers with respect to the center of torsion on the lower floors was considered negligible. The vibration generators were arranged so the sinusoidal forces acted in the N-S direction.

As has been found in tests of other buildings, the natural period increased slightly as the excitation levels were increased, which is characteristic of systems with softening resistance. The acceleration response curves for the first series of tests, $5 \mathrm{a}, 5 \mathrm{~b}$ and $5 \mathrm{c}$ are given in Figure 3 which shows clearly the nonlinearity with amplitude of the building response. Figure 4 shows response curves for the second tests, $8 \mathrm{a}, 8 \mathrm{~b}$ and $\mathrm{Sc}$. In this series test $8 \mathrm{a}$ was made in the evening and tests $8 \mathrm{~b}$ and $8 \mathrm{c}$ the following morning. Comparison of the 8 series tests to the earlier 5 series shows an increase in period between test $5 \mathrm{c}$ and $8 \mathrm{a}$ that is larger than would be expected just from the increase in force level. It is thought that this increase is caused by the materials added to the building during the week between the two test series.

Periods and other response data for both series of tests are given in Table I and the response of the entire building during one of the tests is illustrated by Figure 5 . During the test of N-S fundamental mode the maximum acceleration was $.0194 \mathrm{~g}$ and the maximum displacement was .0534 inches, both observed on the roof. The observed difference between the resonant period at the maximum force level, test $8 \mathrm{~b}$ and at the minimum, test $8 \mathrm{c}$, was 2.9 per cent.

The mode shape found from this data is shown in Fig. 6; in this figure the horizontal deflection of the building is to scale, although the rocking and soil movements are exaggerated. The mode shape from the second floor upward remained nearly constant during the tests, however, the relative displacement of the first floor for the first three tests and then of the basement for the last three tests show a small but 
consistent increase with increasing force level. The mode shape was not affected by changes in the frequency of excitation in the frequency range near resonance.

Figure 6 shows the mode shape to be nearly a straight line, implying that the deflection is a combination of shearing and bending deformations, with shearing deformation dominating in the lower floors. Thus, the end shear walls, with a height to width ratio of about $2.3: 1$, respond like short, deep beams for which shearing deflections are significant.

The damping in this mode of vibration was estimated by the three ways stated above and the computed values from data measured at the roof are presented in Table 2. Damping values computed by the same methods from response curves at other locations, such as those shown in Figure 5, gave the same values to two significant figures and are not included.

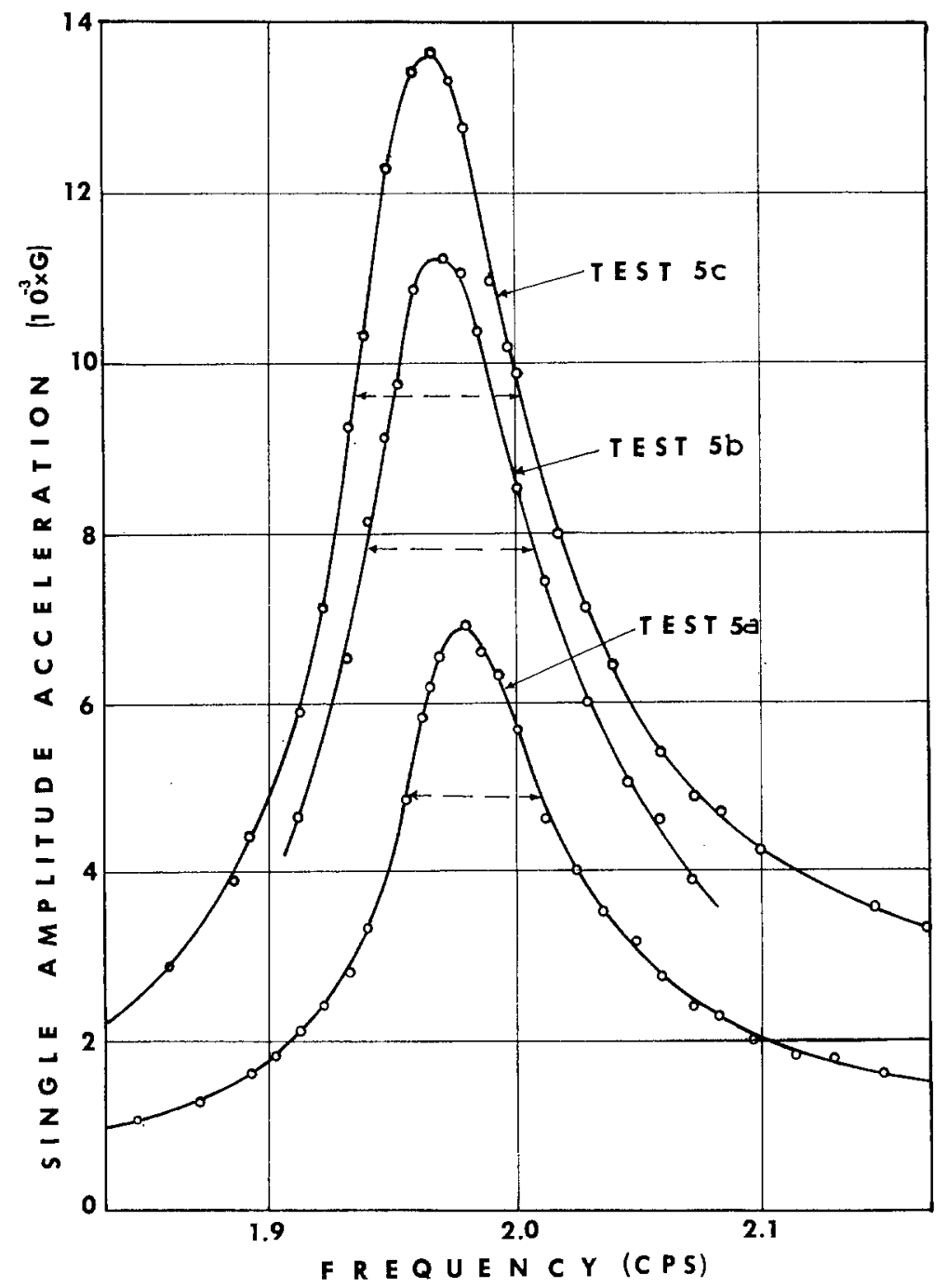

FIG. 3. Roof response for fundamental mode, N-S direction, series 5 tests. 


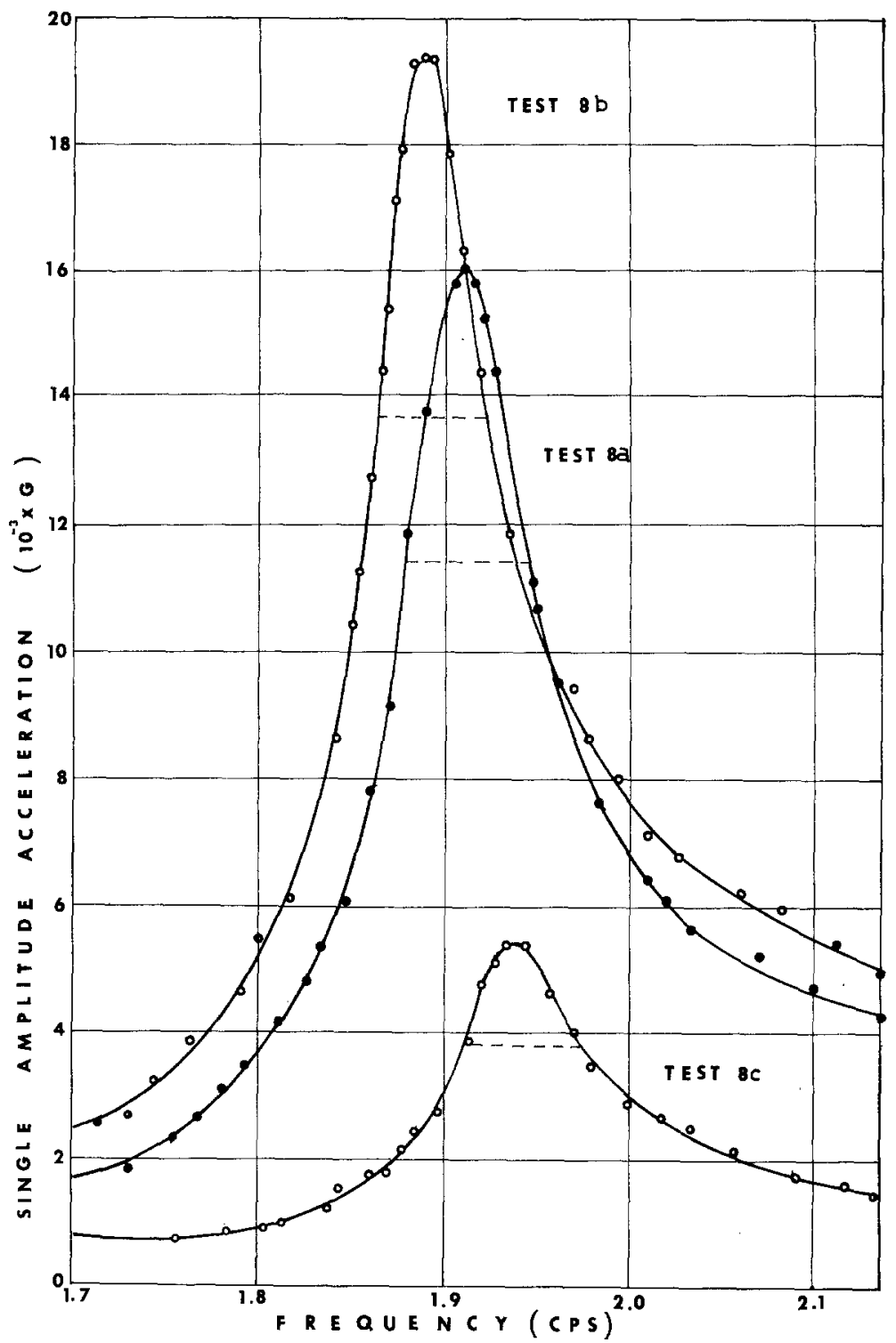

FIG. 4. Roof response for fundamental mode, N-S direction, series 8 tests.

For each group of tests the damping values in Table 2 show a consistent increase with increasing force level, with the exception of test $8 \mathrm{a}$. However, before the data of test 8 a were recorded, the building had been continuously excited at resonance with the test $8 \mathrm{a}$ force level for more than two hours. The response curves for test $8 \mathrm{a}$ were found to be wider than the response curves for the other tests in which the building experienced only about 20 to 50 cycles of response before data were taken. This broadening of the response curve causes the increase in the damping value computed by method I over the results of the other two methods. The other methods, which use 
relations between amplitudes but do not take into consideration the width of the response curve, do not show a larger damping value for test $8 \mathrm{a}$ than for $8 \mathrm{~b}$.

The response curve for test $8 \mathrm{~b}$ (Figure 4 ) shows the sharpness typical of a structure that has experienced a "few cycles" in spite of the fact that in the previous test the building had been excited at 0.8 of the test $8 \mathrm{~b}$ force level for more than two hours. This result suggests that the damping value for a given amplitude may be relatively insensitive to previous vibrations at lower amplitudes.

On the other hand, damping values appear sensitive to previous vibrations at

TABLE I

North-South Fundamental Mode

\begin{tabular}{|c|c|c|c|c|c|c|c|c|c|c|}
\hline Test & $\begin{array}{c}\text { Force at } \\
\text { Resonance } \\
\text { (lbs) }\end{array}$ & $\underset{\text { Period }}{\text { Rec) }}$ & & Roof & 8th & 6th & 4 th & 2nd & 1st & $\begin{array}{l}\text { Base- } \\
\text { ment }\end{array}$ \\
\hline $5 a$ & 1448 & 0.505 & $\begin{array}{l}\text { Acceleration } \\
\quad\left(\mathrm{g} \times 10^{-3}\right) \dagger \\
\text { Displacement } \\
\quad\left(\text { in } \times 10^{-3}\right) \dagger\end{array}$ & $\begin{array}{r}6.95 \\
17.40\end{array}$ & $\begin{array}{r}5.32 \\
13.30\end{array}$ & $\begin{array}{l}3.51 \\
8.80\end{array}$ & $\begin{array}{l}2.33 \\
5.84\end{array}$ & $\begin{array}{l}1.30 \\
3.61\end{array}$ & $\begin{array}{l}0.31 \\
0.78\end{array}$ & \\
\hline $5 b$ & 2620 & 0.507 & & $\begin{array}{l}11.23 \\
28.40\end{array}$ & $\begin{array}{r}8.80 \\
22.20\end{array}$ & $\begin{array}{r}6.39 \\
16.10\end{array}$ & $\begin{array}{r}4.13 \\
10.40\end{array}$ & $\begin{array}{l}1.98 \\
5.00\end{array}$ & $\begin{array}{l}0.64 \\
1.62\end{array}$ & \\
\hline $5 \mathrm{e}$ & 3320 & 0.510 & & $\begin{array}{l}13.64 \\
34.70\end{array}$ & $\begin{array}{l}11.04 \\
28.10\end{array}$ & $\begin{array}{r}8.05 \\
20.50\end{array}$ & $\begin{array}{r}5.23 \\
13.30\end{array}$ & $\begin{array}{l}2.57 \\
6.55\end{array}$ & $\begin{array}{l}0.96 \\
2.44\end{array}$ & \\
\hline $8 a^{*}$ & 4200 & 0.523 & & $\begin{array}{l}16.10 \\
43.10\end{array}$ & $\begin{array}{l}13.10 \\
35.20\end{array}$ & $\begin{array}{r}9.40 \\
25.20\end{array}$ & $\begin{array}{r}6.40 \\
17.20\end{array}$ & $\begin{array}{l}2.97 \\
7.96\end{array}$ & & $\begin{array}{l}0.38 \\
1.02\end{array}$ \\
\hline $8 b^{*}$ & 5430 & 0.530 & & $\begin{array}{l}19.40 \\
53.40\end{array}$ & $\begin{array}{l}15.35 \\
42.20\end{array}$ & $\begin{array}{l}11.00 \\
30.30\end{array}$ & $\begin{array}{r}7.50 \\
20.60\end{array}$ & $\begin{array}{r}3.72 \\
10.20\end{array}$ & & $\begin{array}{l}0.47 \\
1.29\end{array}$ \\
\hline $8 c^{*}$ & 1382 & 0.515 & & $\begin{array}{r}5.38 \\
14.10\end{array}$ & $\begin{array}{r}4.21 \\
11.00\end{array}$ & $\begin{array}{l}2.75 \\
7.26\end{array}$ & $\begin{array}{l}1.82 \\
4.76\end{array}$ & $\begin{array}{l}1.03 \\
? .69\end{array}$ & & $\begin{array}{l}0.057 \\
0.149\end{array}$ \\
\hline
\end{tabular}

$\dagger$ Single amplitude values.

* The 8 series tests were conducted one week after the 5 series tests.

higher amplitudes. Test $8 \mathrm{c}$ was performed with the same eccentric masses as test $5 \mathrm{a}$ after the completion of the intervening tests, one of which, $8 \mathrm{~b}$, had a maximum response roughly three times that of 5a. The damping found from test $8 \mathrm{c}$ was larger than would be expected from the amplitude of response, being only 10 per cent less than that found from test $8 \mathrm{~b}$ and about 20 per cent greater than the value from $5 \mathrm{a}$.

Figure 4 shows another effect of history upon the response. Test 8 a was performed on a Saturday afternoon and test $8 \mathrm{~b}$ on the following morning. The crossing of the response curves and the amount of change in the natural period between the tests indicates that a structural change had taken place between the tests, presumably as a consequence of the rest period.

$E-W$ Translational Modes. For the E-W tests accelerometers were placed on the 10th, 8th, 6th, 4th, 2nd and basement floors, on the E-W centerline 8 feet from the east elevator wall. In this direction all tests were performed during the same week- 


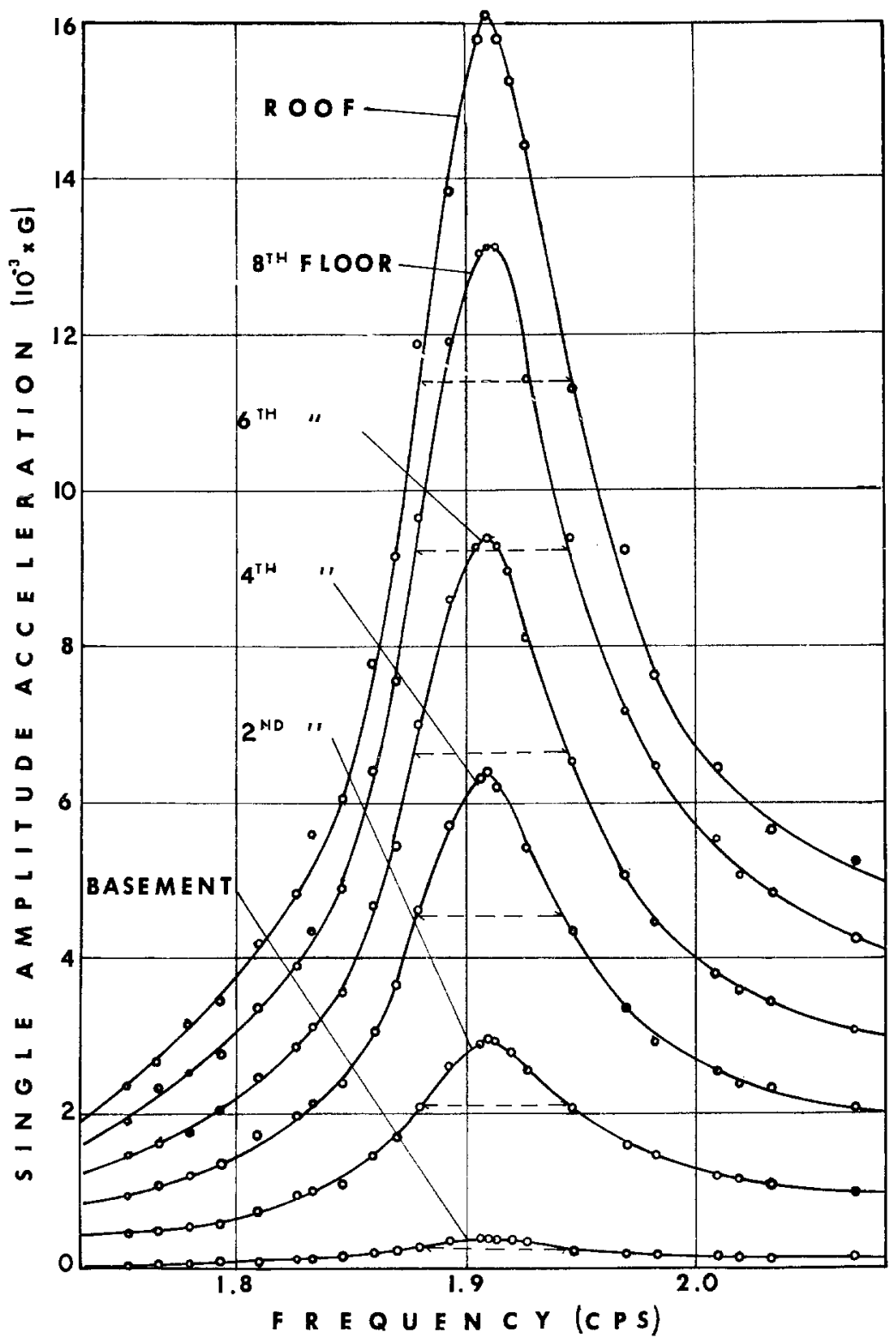

FIG. 5. Response curves for test 8 a, recorded at different floors.

end, so no mass or stiffness was added between tests. The building showed an increase of 2.7 per cent in the resonant period of the first mode between the lowest and highest levels of the exciting forces (ratio 1 to 7.5). This result is seen in Figure 7 in which the resonant frequency is plotted versus the displacement at resonance. It is seen that the frequency decreases approximately linearly with amplitude over the range of data. Resonance curves for the 8th floor response are shown in Figure 8 , in which the numbers indicate the sequence of the tests, which were all performed with increasing frequency steps. 
The results for the E-W fundamental mode are summarized in Table 3 in which it is seen that the maximum acceleration was $.0167 \mathrm{~g}$ on the roof and the corresponding maximum displacement .0752 in. The shape of the first mode was not well-defined for the lowest level of excitation but remained constant with further increases in the force level. The E-W mode shape is shown in Figure 9, in which only the horizontal displacements of the building are to scale.

The damping values for the first mode excitation in the $\mathrm{E}-\mathrm{W}$ direction, calculated from data recorded at roof level, are given in Table 4 . The results show that the

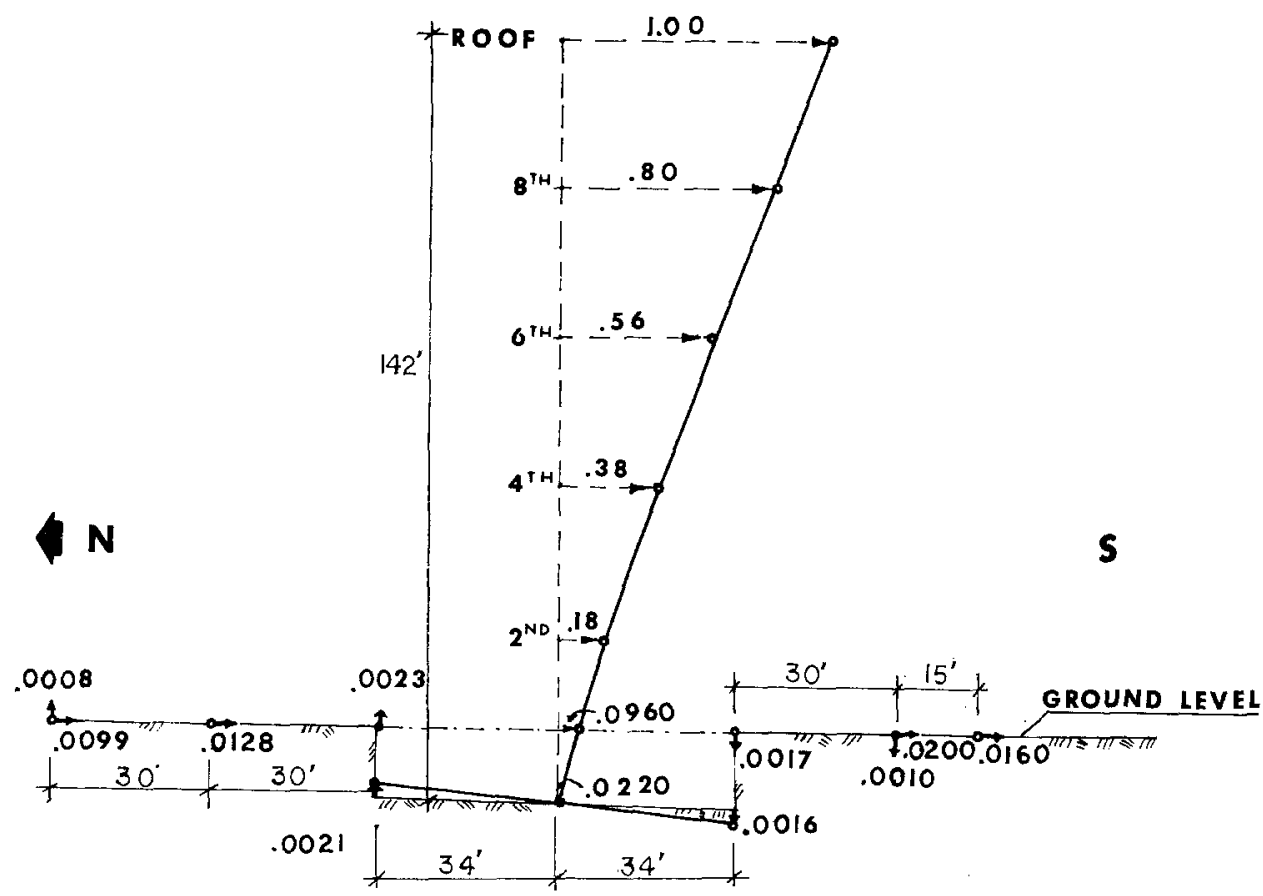

Frg. 6. Relative motion of the building and the nearby ground, N-S fundamental mode (not to scale).

TABLE II

Damping in Percentage of Critical N-S Fundamental Mode

\begin{tabular}{ccccc}
\hline Test & $\begin{array}{c}\text { Displacement } \\
\text { Amplitude Ratio }\end{array}$ & Method I & Method II & Method III \\
\hline $5 \mathrm{a}$ & 1.00 & 1.16 & 1.24 & 1.44 \\
$5 \mathrm{~b}$ & 1.62 & 1.45 & 1.35 & $\dagger$ \\
$5 \mathrm{c}$ & 1.97 & 1.48 & 1.39 & 1.51 \\
& & & & \\
$8 \mathrm{a}$ & 2.45 & $1.75^{*}$ & 1.49 & 1.88 \\
$8 \mathrm{~b}$ & 3.02 & 1.64 & 1.60 & 1.93 \\
$8 \mathrm{c}$ & 0.79 & 1.54 & 1.47 & 1.74 \\
\hline
\end{tabular}

$\uparrow$ Insufficient data to apply this method.

* See text. 
damping consistently increased with increased response, changing a total of roughly 50 per cent within the testing range.

The results for the second E-W translational mode are summarized in Figure 10. Because of interest in other features of the response, this mode was not investigated extensively. It is seen from Figure 10 that the periods and mode shapes corresponding to this mode were not well-defined. The maximum acceleration at different floors did not occur at the same instant, and the peak responses of the different floors did not occur at the same frequency. The E-W motion was accompanied by N-S movement, indicating combined torsional and translational motion. Such complexity in

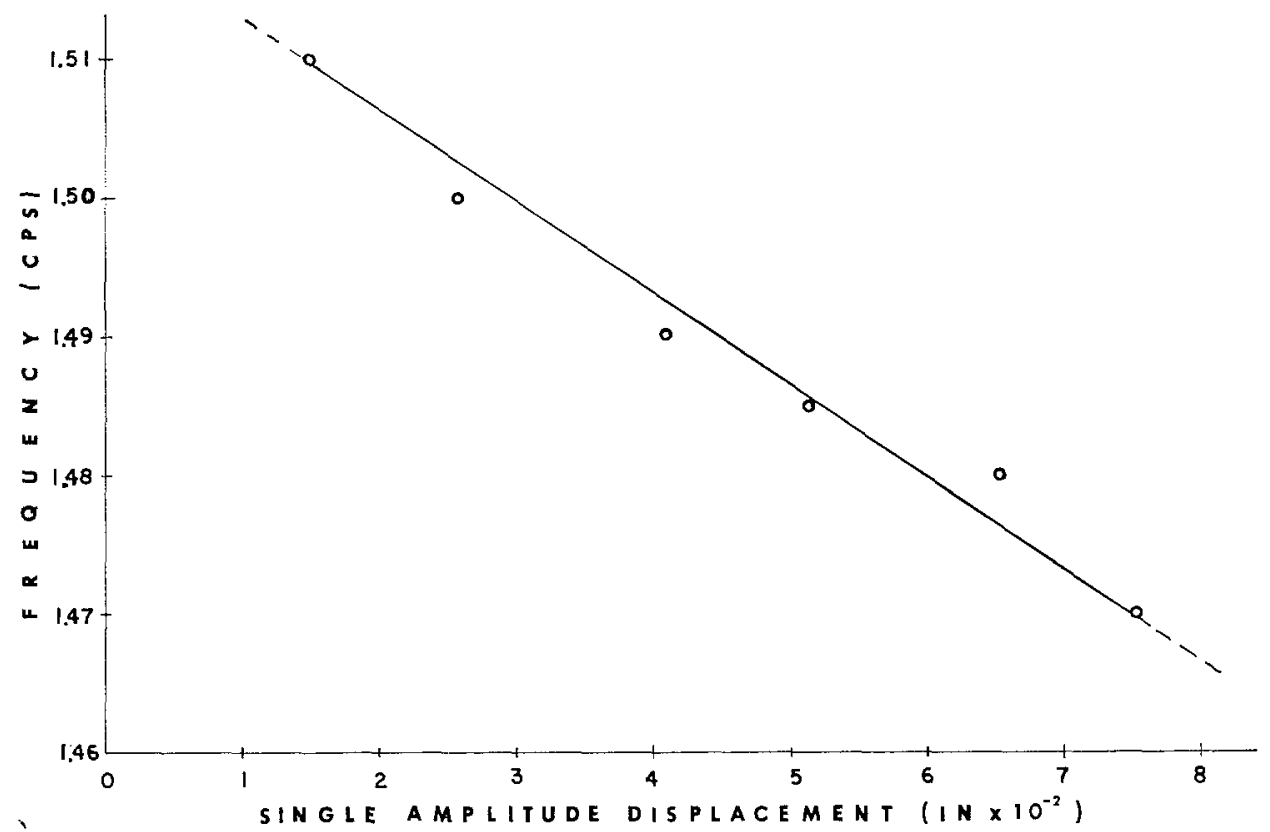

FIG. 7. Resonant frequency as a function of amplitude. E-W fundamental mode.

one of the second modes is noteworthy in view of the symmetry of the building and the simplicity of the response in the fundamental modes.

Torsional Mode. For the torsional tests only the east side vibrator was used, generating forces in the $\mathrm{N}-\mathrm{S}$ direction. The accelerometers were oriented $\mathrm{N}-\mathrm{S}$ and located over the $\mathrm{E}-\mathrm{W}$ centerline, 8 feet from the east shear wall, on the $10 \mathrm{th}, 8 \mathrm{th}, 6 \mathrm{th}, 4 \mathrm{th}$, 2nd and basement floors.

The behavior of the building in vibration in the fundamental torsional mode was qualitatively similar to the response in the translational modes and is shown in Figure 11. The results are summarized in Table 5 which gives the acceleration and disdisplacements at the accelerometer locations. Because of the locations of the accelerometers, and of the small eccentricity of the building, the relative values of the floor deflections are very nearly equal to the relative rotations of the floors.

In the torsional tests also the damping increased with the increase of the amplitude of vibration as shown in Table 6 . It is seen that these damping values are less than those found for the translational modes. 
Measurements at Very Low Force Levels. Before the vibration generators were installed and after they were removed the natural periods of vibration and damping of the building in the fundamental modes in the N-S and E-W directions were measured using the Lunar Seismometer, exciting the structure with a rhythmical move-

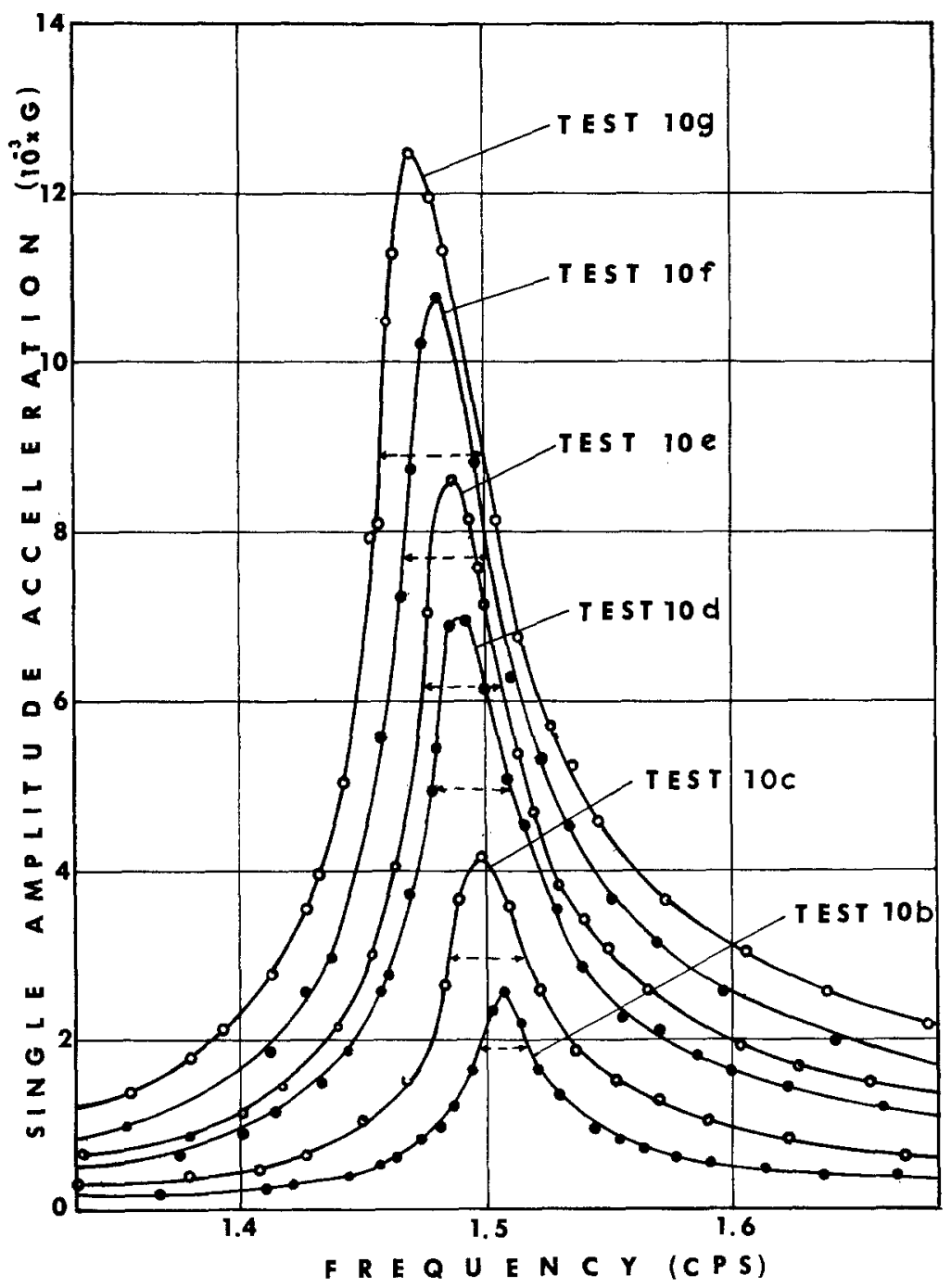

FIG. 8. Response of the 8th floor in the fundamental mode; E-W direction.

ment of the operator's body. This type of vibration has been called "man excited vibration" (Hudson et al, 1964). These measurements were used to study the influence of the precast concrete window panels on the dynamic response of the building, and also to measure the natural period of vibration and the damping of the building at very low force levels. The periods measured are given in Table 7 .

The addition of the precast panels to the building increased both the mass and stiffness of the structure but the effects on the fundamental periods were not the 
TABLE III

East-West Fundamentat Mode

\begin{tabular}{|c|c|c|c|c|c|c|c|c|c|}
\hline Test & $\begin{array}{c}\text { Force at } \\
\text { Resonance } \\
\text { (lbs) }\end{array}$ & $\begin{array}{l}\text { Resonant } \\
\text { Period } \\
\text { (sec) }\end{array}$ & & Roof & $8 \mathrm{tb}$ & 6th & 4th & 2nd & Basement \\
\hline \multirow[t]{2}{*}{$10 \mathrm{~b}$} & 432 & 0.662 & $\begin{array}{l}\text { Acceleration } \\
\quad\left(\mathrm{g}=10^{-3}\right) \dagger\end{array}$ & 3.52 & 2.34 & 1.59 & 0.95 & 0.36 & 0.011 \\
\hline & & & $\begin{array}{l}\text { Displacement } \\
\quad\left(\text { in } \times 10^{-3}\right) \dagger\end{array}$ & 14.90 & 9.92 & 6.75 & 4.13 & 1.53 & 0.047 \\
\hline \multirow[t]{2}{*}{$10 \mathrm{c}$} & 834 & 0.666 & & 5.94 & 4.17 & 2.79 & 1.67 & 0.68 & 0.018 \\
\hline & & & & 25.50 & 17.90 & 12.00 & 7.16 & 2.92 & 0.077 \\
\hline \multirow[t]{2}{*}{$10 \mathrm{~d}$} & 1495 & 0.671 & & 9.36 & 6.96 & 4.25 & 2.72 & 1.05 & 0.029 \\
\hline & & & & 40.80 & 30.40 & 18.60 & 11.90 & 4.57 & 0.129 \\
\hline \multirow[t]{2}{*}{$10 \mathrm{e}$} & 1890 & 0.673 & & 11.55 & 8.61 & 5.30 & 3.30 & 1.24 & 0.038 \\
\hline & & & & 51.30 & 38.20 & 23.50 & 14.60 & 5.50 & 0.168 \\
\hline \multirow[t]{2}{*}{$10 \mathrm{f}$} & 2620 & 0.676 & & 14.50 & 10.71 & 6.70 & 4.10 & 1.58 & $0.032^{*}$ \\
\hline & & & & 65.20 & 48.20 & 30.20 & 18.40 & 7.10 & 0.144 \\
\hline \multirow[t]{2}{*}{$10 \mathrm{~g}$} & 3290 & 0.680 & & 16.70 & 12.50 & 7.70 & 4.62 & 1.78 & 0.054 \\
\hline & & & & 75.20 & 56.60 & 34.90 & 21.00 & 8.07 & 0.245 \\
\hline
\end{tabular}

$\dagger$ Single amplitude values.

* Amplifier malfunction.

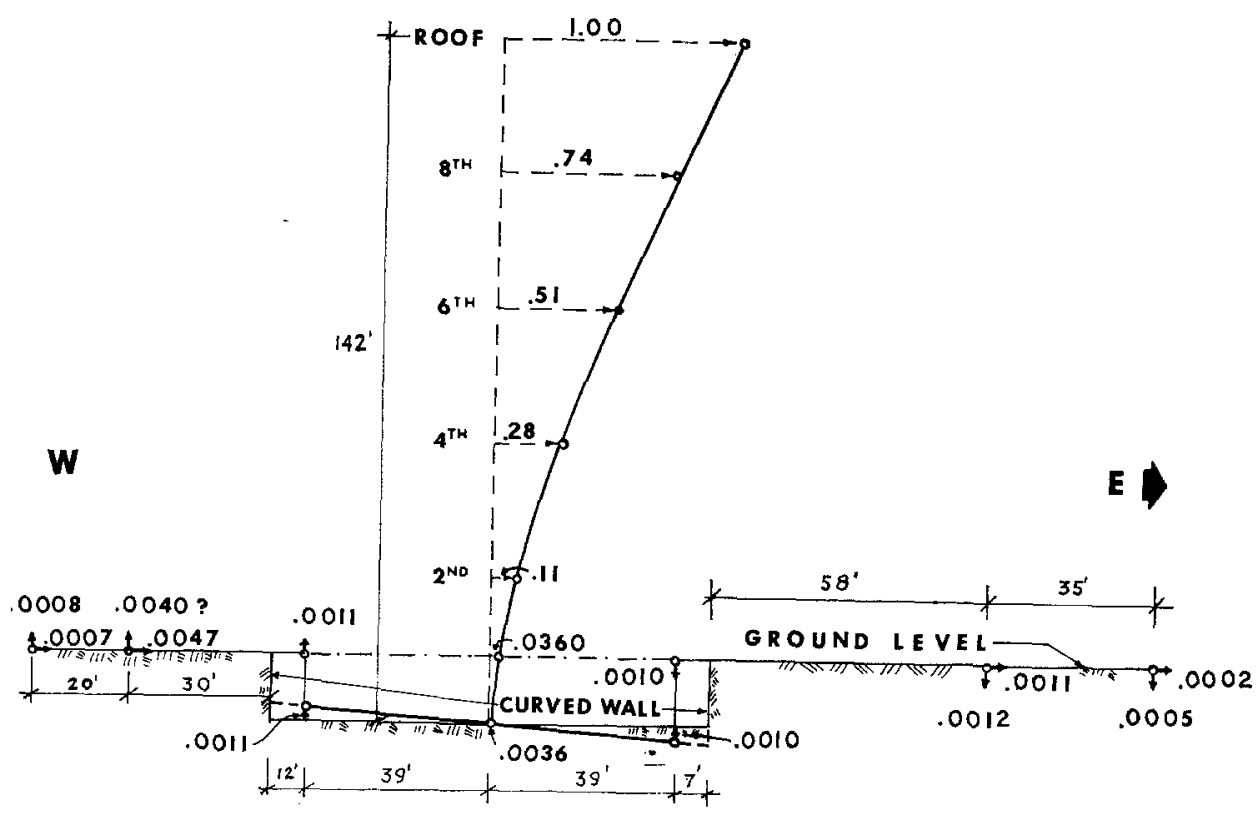

FIG. 9. Relative motion of the building and the nearby ground; E-W fundamental mode (not to scale). 
TABLE IV

Damping in Percentage of Critical E-W Fundamental Mode

\begin{tabular}{ccccc}
\hline Test & $\begin{array}{c}\text { Displacement } \\
\text { Amplitude Ratio }\end{array}$ & Method I & Method II & Method III \\
\hline $10 \mathrm{~b}$ & 1.00 & 0.69 & 0.80 & 0.97 \\
$10 \mathrm{c}$ & 1.71 & 1.06 & 0.89 & 0.96 \\
$10 \mathrm{~d}$ & 2.74 & 1.12 & 0.97 & 1.17 \\
$10 \mathrm{e}$ & 3.44 & 1.12 & 1.01 & 1.15 \\
$10 \mathrm{f}$ & 4.38 & 1.21 & 1.16 & $*$ \\
$10 \mathrm{~g}$ & 5.08 & 1.48 & 1.20 & 1.50
\end{tabular}

* Insufficient data to apply this method.
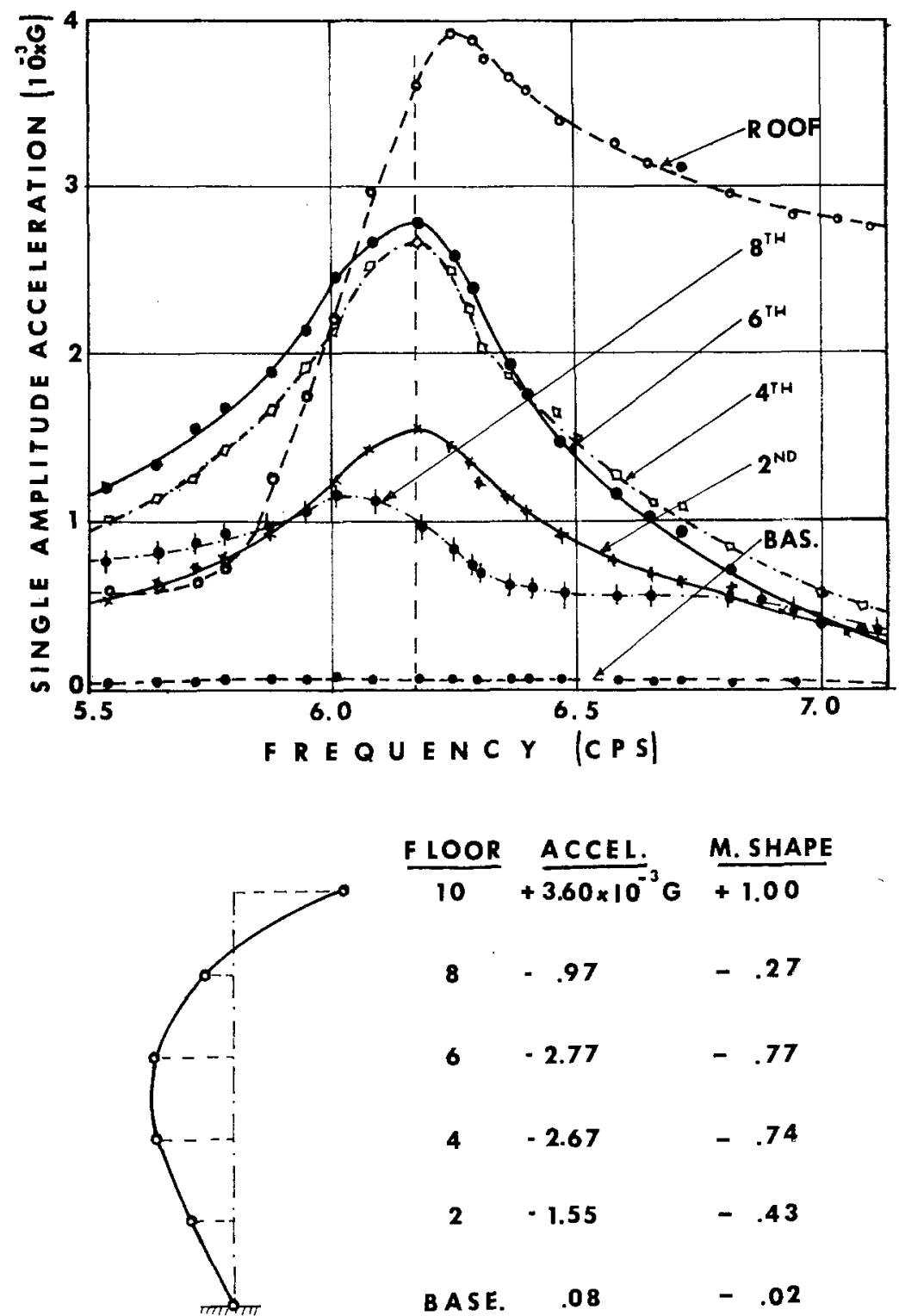

FIG. 10. Above: response at different floors in the second mode, E-W direction; Below: mode shape at $6.2 \mathrm{cps}$ (Test 10b). 


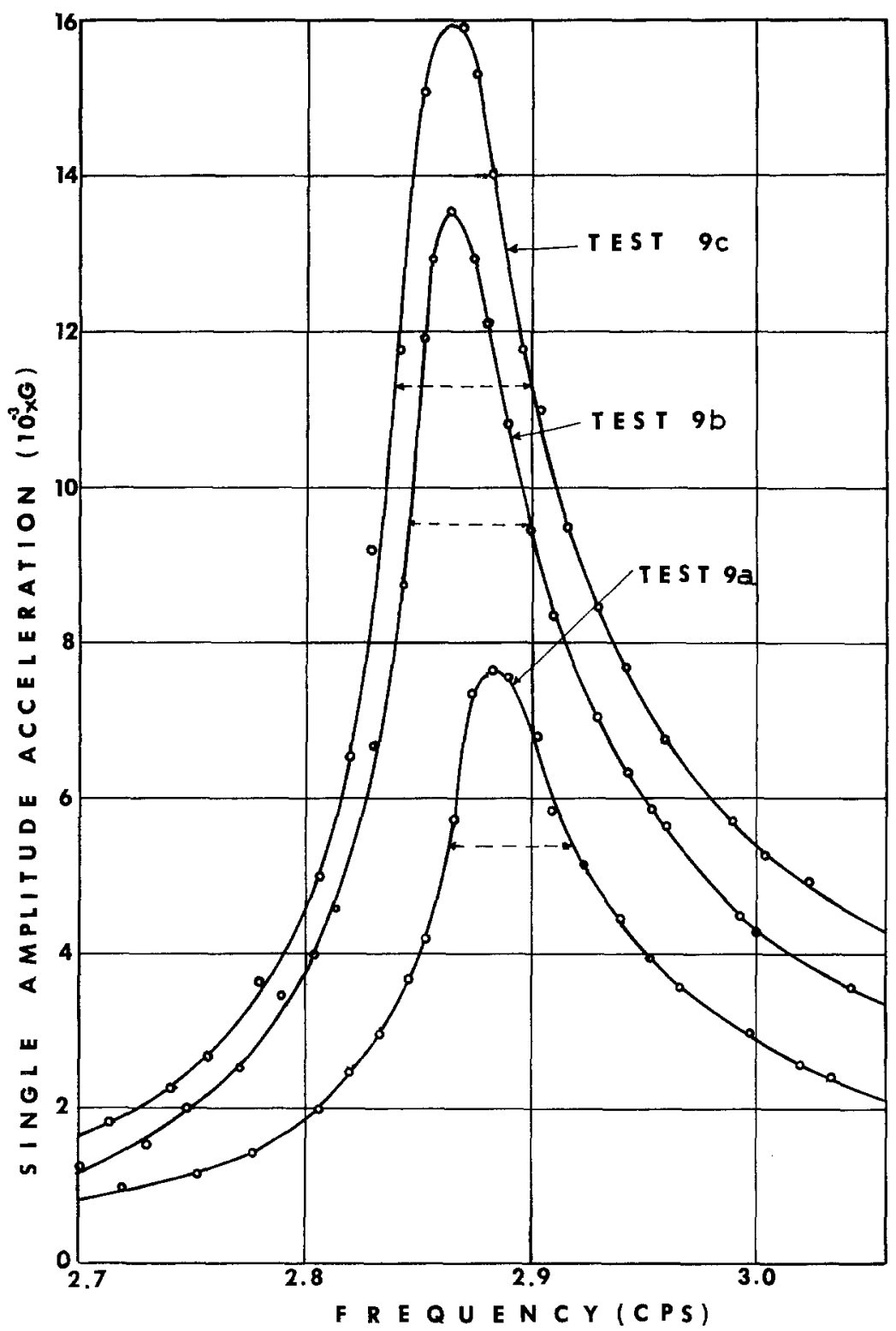

Fig. 11. Eighth floor response for the fundamental torsional mode.

same in the two directions. The natural period was increased in the N-S direction, but decreased in the $\mathrm{E}-\mathrm{W}$ direction, i.e., in the $\mathrm{N}$-S direction it was the increase of mass that had the predominant effect, but in the E-W direction the increased stiffness exceeded the effects of increased mass. These effects are consistent with what could be expected from the building geometry shown in Figure 1.

The execution of the finishing work had the same effect on the periods as the placing of the north and south side facades. This work included the placement of granite 
TABLE V

Fundanental Mode in Torsion

\begin{tabular}{|c|c|c|c|c|c|c|c|c|c|}
\hline Test & $\begin{array}{l}\text { Force at } \\
\text { Resonance } \\
\text { (lbs) }\end{array}$ & $\begin{array}{c}\text { Resonant } \\
\text { Period (sec) }\end{array}$ & & Roof & 8th & 6 th & 4th & 2nd & $\begin{array}{l}\text { Base- } \\
\text { ment }\end{array}$ \\
\hline \multirow[t]{2}{*}{$9 a$} & 1535 & 0.346 & $\begin{array}{l}\text { Acceleration } \\
\qquad\left(\mathrm{g} \times 10^{-3}\right) \dagger\end{array}$ & 9.80 & 7.64 & 5.30 & 1.63 & 1.36 & 0.24 \\
\hline & & & $\begin{array}{l}\text { Displacement } \\
\quad\left(\text { in } \times 10^{-3}\right) \dagger\end{array}$ & 11.60 & 9.00 & 6.25 & 1.92 & 1.61 & 0.28 \\
\hline \multirow[t]{2}{*}{$9 b$} & 2775 & 0.349 & & 16.50 & 13.50 & 10.15 & 3.62 & 2.77 & 0.42 \\
\hline & & & & 19.60 & 16.00 & 1.210 & 4.30 & 3.30 & 0.50 \\
\hline \multirow[t]{2}{*}{$9 \mathrm{c}$} & 3525 & 0.350 & & 19.70 & 15.95 & 11.90 & 4.20 & 3.27 & 0.50 \\
\hline & & & & 23.60 & 19.10 & 14.30 & 5.03 & 3.92 & 0.60 \\
\hline
\end{tabular}

$\dagger$ Single amplitude values of translation at recording points.

TABLE VI

Damping in Percentage of Critical Damping Fundamental Mode IN TORSION

\begin{tabular}{ccccc}
\hline Test & $\begin{array}{c}\text { Displacement } \\
\text { Amplitude Ratio }\end{array}$ & Method I & Method II & Method III \\
\hline $9 \mathrm{a}$ & 1.00 & 0.93 & 0.98 & 1.51 \\
$9 \mathrm{~b}$ & 1.70 & 0.96 & 0.99 & 1.40 \\
$9 \mathrm{c}$ & 2.04 & 1.05 & 1.06 & 1.65 \\
\hline
\end{tabular}

TABLE VII

Changes of Bullding Periods with Construction

\begin{tabular}{|c|c|c|c|}
\hline Direction & Period (sec) & Instrument & Building Condition \\
\hline $\mathrm{N}-\mathrm{S}$ & 0.46 & Lunar seismometer & $\begin{array}{l}\text { Before the precast wall panels were } \\
\text { placed }\end{array}$ \\
\hline $\mathrm{N}-\mathrm{S}$ & 0.49 & Exciter A, lowest force level & After north side facade was placed \\
\hline $\mathrm{N}-\mathrm{S}$ & 0.505 & Exciter A, lowest force level & After both facades were placed \\
\hline $\mathrm{N}-\mathrm{S}$ & 0.52 & Lunar seismometer & $\begin{array}{l}\text { After the finishing work was com- } \\
\text { pleted }\end{array}$ \\
\hline $\mathrm{E}-\mathrm{W}$ & 0.71 & Lunar seismometer & $\begin{array}{l}\text { Before the precast wall panels were } \\
\text { placed }\end{array}$ \\
\hline $\mathrm{E}-\mathrm{W}$ & 0.67 & Exciter B, lowest force level & After north side facade was placed \\
\hline $\mathrm{E}-\mathrm{W}$ & 0.67 & Exciter B, lowest force level & After both facades were placed \\
\hline $\mathrm{E}-\mathrm{W}$ & 0.64 & Lunar seismometer & $\begin{array}{l}\text { After the finishing work was com- } \\
\text { pleted }\end{array}$ \\
\hline
\end{tabular}

plates on the end walls of the building and covering of the joints between the precast concrete panels and the building by beam-like elements.

It was found that after having some practice in using the Lunar Seismometer it was possible to maintain the man excitation at a fairly constant force level as judged by the response. Then, by stopping the excitation and observing the decay of 
free vibrations, damping values were found. A record from one of these tests is shown in Figure 12. The percentage of critical viscous damping computed using this method varied between 0.6 to 0.9 per cent in the N-S direction and from 0.6 to 0.8 per cent in the $\mathrm{E}-\mathrm{W}$ direction. This indicates the high degree of nonlinearity in the energy dissipation characteristics of the building in that these damping factors are only onethird to one-half those found from the highest levels of the other tests.

Vibration of Equipment on the Roof. The usual practice with buildings of intermediate height is to locate the elevator and air conditioning equipment on the roof.

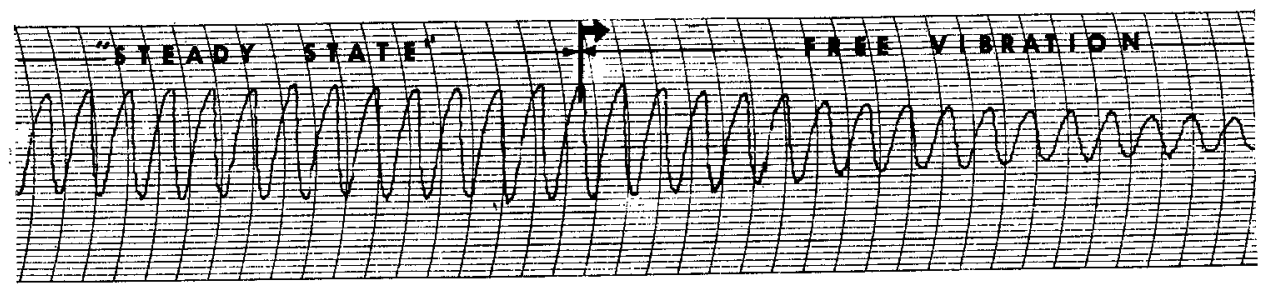

FIG. 12. Record taken with the Lunar Seismometer of "Man-excited Vibrations."

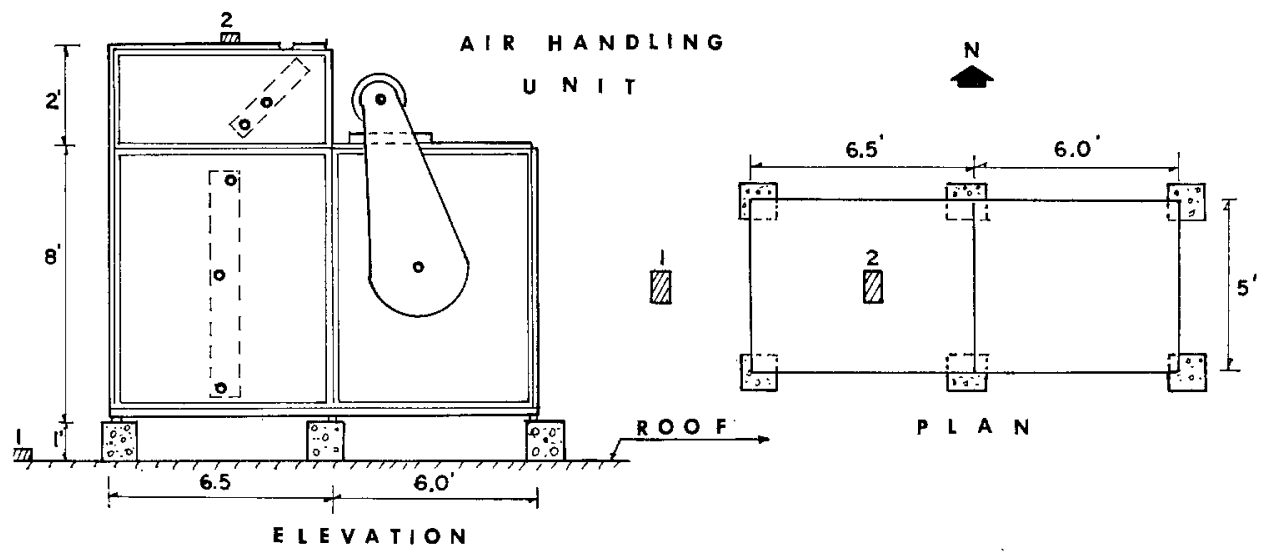

FIG. 13. Plan and elevation views of the air handling unit. The numbers 1 and 2 indicate accelerometer locations.

If a piece of this equipment has a natural frequency close to one of the lower natural frequencies of the structure, it may act as a vibration amplifier and be violently shaken during either an earthquake or a vibration test of the structure. The rooftop location of the equipment tends to magnify over other locations any effects that might occur. This problem, which has important practical applications, has been the subject of recent theoretical studies (Penzien and Chopra, 1965; Skinner et al, 1965).

During the vibration tests in the N-S direction, it was noticed among the roof-top machinery that the vibration of an air handling unit was much greater than that of the other pieces of equipment. The vibration amplification was measured by placing one horizontal accelerometer on the roof and another on the top of the air handling unit as shown in Figure 13. It was found that the acceleration measured on the top 
of the air handling unit was about 8.5 times the acceleration of the roof. The values of the accelerations recorded were

$$
\begin{array}{ll}
\text { Roof } & .0158 \mathrm{~g} \\
\text { Air handling unit } & .123 \mathrm{~g} .
\end{array}
$$

Because the roof acceleration in this test is much less than would be expected in even a moderate earthquake, the response of such equipment could conceivably reach very high levels. It should be noted that this particular piece of equipment has since been stiffened by the completion of the duct work, piping, etc., but the earthquake resistance of these elements is probably not large.

\section{SOIL-STRUCTURE INTERACTION}

When a simplified structural analysis of a building is made for the common type of soils encountered on the west coast, it is usually supposed that the building is fixed at the ground level. For more accurate analyses the foundation-ground interaction is assumed to satisfy certain analytic relations, so the problem can be resolved, usually with the aid of a computer. Several mathematical models for the coupling have been proposed and there is a considerable body of literature on the general problem, for example, the recent study by Parmelee (1967). However, building motion below ground level has not been specifically investigated in this country during a building vibration test and, in general, there is little experimental data available on soil-structure interaction.

It was thought that the Millikan Library Building, because of its relatively high density, significantly different stiffnesses in the N-S and E-W directions, and substantial basement, would be a particularly good building to use to investigate experimentally the problem of soil-structure interaction. Two aspects of the problem were studied: the basement motion and the vibration of the ground surface in the vicinity of the building.

Soil Properties. The soil properties at the construction site were investigated by Converse Foundation Engineers of Pasadena several years before construction was initiated (Converse Foundation Engineers, 1959). The soils were examined by drilling four borings, one at each corner of a $112^{\prime} \times 62^{\prime}$ rectangle with the longer dimension oriented N-S, and by a fifth hole at the center of the rectangle, a point almost coincident with the present center of the building. One to two feet of fill soil was found in the two west side borings but no fill was noted in the others. Otherwise, all the borings show practically the same results. The results of the boring at the center of the rectangle are shown in Figure 14. The basement excavation was made to such a depth that the footing rested on firm undisturbed natural soil, about 18 feet below the ground level.

Basement Motion. The horizontal displacement at the ground and basement floors, and the rocking vibration of the building on its base were measured during vibration in the fundamental modes in the N-S and E-W directions. During the tests in each direction horizontal accelerometers were placed on the roof, 6th, ground and basement floors exactly as for the translational tests. Two vertical accelerometers were placed on the basement floor at opposite ends on the N-S centerline for 
the N-S tests, and at opposite ends of the E-W centerline for the E-W tests; these locations are shown in Figure 15. Each test was made at the first mode resonant frequency of that direction, the resonant exciting forces were $5430 \mathrm{lbs}$ in the N-S direction and $2740 \mathrm{lbs}$ in the $\mathrm{E}-\mathrm{W}$ direction.

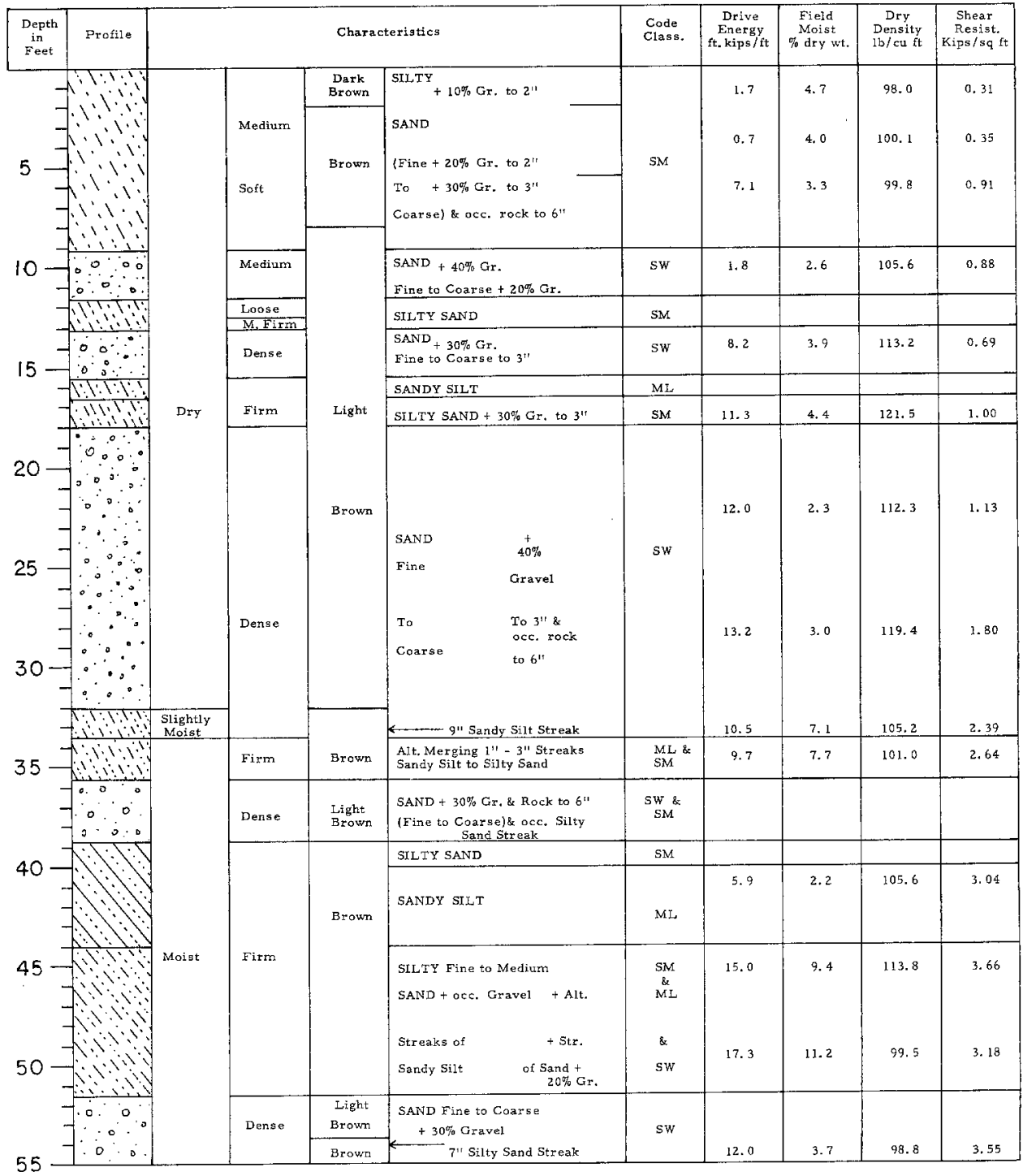

Fig. 14. Summary of test results for boring No. 2, Millikan Library Foundation exploration.

As a result of these tests it was found that in the stiffer N-S direction the horizontal ground floor motion was 9.6 per cent of the roof motion and the basement motion 2.2 per cent. In the more flexible E-W direction the ground floor motion was found to be 4.0 per cent of the roof motion and the basement motion 0.3 per cent. 
Measurable rocking of the structure was indicated by the vertical accelerometers. Rocking contributed a horizontal displacement at the top of the building of 0.8 per cent of the total deflection in the N-S direction and 0.4 per cent in the $\mathrm{E}-\mathrm{W}$ direction. As far as the building dynamics are concerned, these amounts are negligible. The results of these tests agree with the conclusions of studies made by G. W. Merrit and G. W. Housner (Merritt and Housner, 1954; Housner, 1957), that is, for ordinary structures significant rocking effect is expected only in exceptionally soft ground, which is not the case at the Millikan Building site.

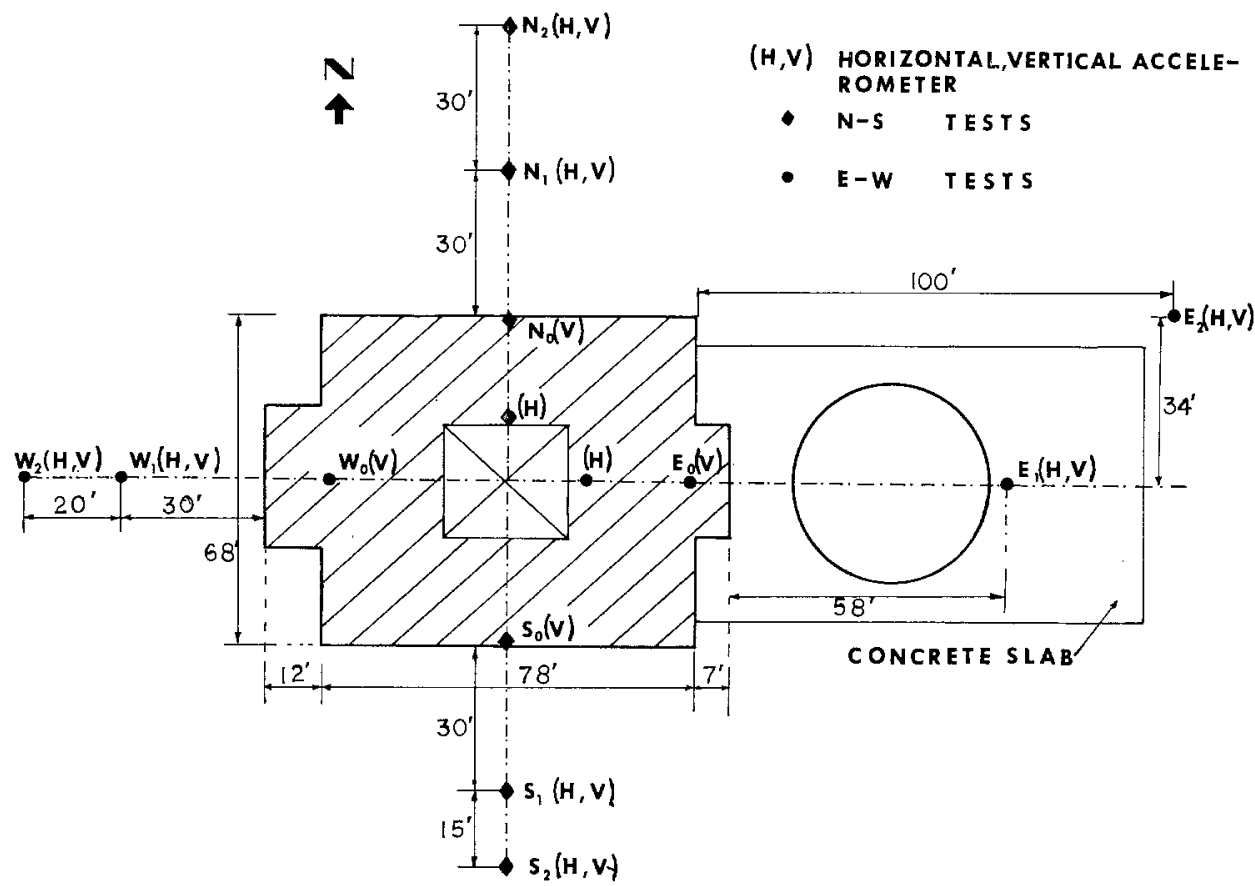

FIG. 15. Location of the accelerometers during the soil-structure interaction, tests.

From the test results it is apparent that the compacted backfill surrounding the basement could not prevent horizontal motion of the part of the building below ground level and during tests the building moved much as if no backfill were present at all. Such behavior is reasonable because, as seen in Figures 6 and 9 , the horizontal building displacement increases upward from a negligible amplitude at the basement level, while at the same time the passive resistance of the soil to this deflection decreases upward, as the depth of soil becomes less.

The situation is quite different for the soils underneath the building. These relatively undisturbed soils had been steadily and increasingly loaded during the construction period and at the time the building was completed these soils had the strength to resist the rocking and translational deformations.

In simplified seismic analyses of buildings with conditions similar to those existing at the Millikan Library, the results show that it would be more realistic to consider the building fixed at the foundation than at ground level.

Vibration of the Nearby Ground. The displacement of the ground surface near the 
building was measured by recording the vertical and horizontal displacements at different distances from the structure. The tests were performed in the N-S and E-W directions by exciting the building in each direction with constant amplitude, at the resonant frequency of the lowest translational mode. A horizontal accelerometer located on the roof and another on the ground floor were used for control and reference and were maintained fixed in those locations throughout the tests in each direction, while two sets of horizontal and vertical accelerometers were moved around outside the building. There were two sets of outside accelerometers, each set consisting of one vertical and one horizontal accelerometer on a forty pound steel plate. The plate was carefully placed on about a $\frac{1}{2}$ inch layer of sand on the surface of the ground at the recording sites.

TABLE VIII

Relative Horizontal Displacement of the Ground

\begin{tabular}{ccccc}
\hline $\begin{array}{c}\text { Location (See } \\
\text { Fig. 15) }\end{array}$ & $\begin{array}{c}\text { Distance from } \\
\text { Building (feet) }\end{array}$ & Building Motion & \multicolumn{2}{c}{$\begin{array}{c}\text { Horizontal Displacement as } \\
\text { a Percentage }\end{array}$} \\
\hline $\mathrm{N}_{1}$ & $30^{\prime} \mathrm{N}$ & $\mathrm{N}-\mathrm{S}$ & 14 & 61 \\
$\mathrm{~N}_{2}$ & $60^{\prime} \mathrm{N}$ & $\mathrm{N}-\mathrm{S}$ & 11 & 48 \\
displacement & $\begin{array}{c}\text { of basement } \\
\text { displacement }\end{array}$ \\
$\mathrm{S}_{1}$ & $30^{\prime} \mathrm{S}$ & $\mathrm{N}-\mathrm{S}$ & 21 & 91 \\
$\mathrm{~S}_{2}$ & $45^{\prime} \mathrm{S}$ & $\mathrm{N}-\mathrm{S}$ & 17 & 73 \\
$\mathrm{~W}_{1}$ & $30^{\prime} \mathrm{W}$ & $\mathrm{E}-\mathrm{W}$ & 13 & $130^{*}$ \\
$\mathrm{~W}_{2}$ & $50^{\prime} \mathrm{W}$ & $\mathrm{E}-\mathrm{W}$ & 3 & 30 \\
$\mathrm{E}_{1}$ & $58^{\prime} \mathrm{E}$ & $\mathrm{E}-\mathrm{W}$ & 3 & 30 \\
$\mathrm{E}_{2}$ & $100^{\prime} \mathrm{E}$ & $\mathrm{E}-\mathrm{W}$ & 1 & 10 \\
\hline
\end{tabular}

* See text.

The locations of the accelerometers and the types used at each point may be seen in Figure 15. It was not possible always to place the accelerometers symmetrically with respect to the building because of architectural features and the desire to locate the instruments over undisturbed soils. Symmetric placement was possible for the N-S tests, but not for the $\mathrm{E}$-W tests.

The amplitudes of the ground vibration normalized with respect to the motion of the roof are shown in Figure 6 for the N-S tests and in Figure 9 for the E-W tests, and the horizontal displacements of the ground, expressed as percentages of the displacements of the first and basement floors, are given in Table 8.

The vertical displacements of the ground, normalized with respect to the vertical displacements of the north edge of the first floor for the N-S direction, and with respect to the vertical displacement of the west shear wall at the first floor level for the E-W direction, are shown in Figure 16.

The results of the N-S ground motion tests are more consistent than those for the $\mathrm{E}-\mathrm{W}$ direction. It is thought that this is due to the simpler geometry existing in the $\mathrm{N}-\mathrm{S}$ direction, as seen in Figures 1 and 15. Also the accelerometers were placed over undisturbed soil in the N-S tests, but not in the E-W tests. The actual placing of the accelerometers for the $\mathrm{E}-\mathrm{W}$ tests was as follows: On the east side, at $\mathrm{E}_{1}$ (see Figure 15), and at the edge of the memorial pool excavation, $34^{\prime} \mathrm{N}$ of the E-W 
centerline, at $\mathrm{E}_{2}$. On the west side, on a construction roadway, it was not possible to get any signal at a point $60^{\prime} \mathrm{W}$ from the building. At $50^{\prime} \mathrm{W}$ (location $\mathrm{W}_{2}$ in Figure 15), the horizontal component of the recorded acceleration was very small with respect to the horizontal acceleration recorded $20^{\prime}$ closer to the building at $W_{1}$, where the accelerometers were placed over soil which had not been disturbed during construction.

The fact that the horizontal displacement of the ground recorded at $W_{1}$ was larger than that of the basement floor (the value marked with the asterisk in Table 8), seems to indicate that at least part of the energy was being transferred laterally
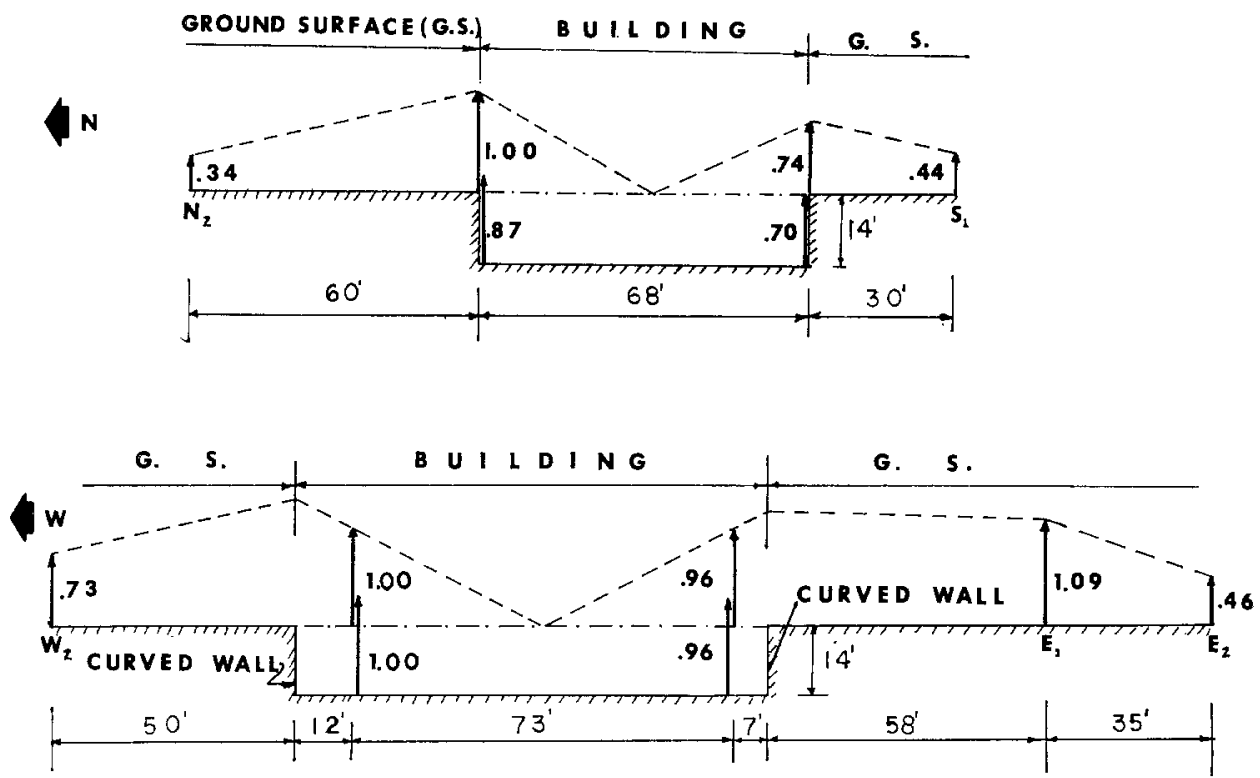

FIG. 16. Relative vertical movement of the basement and nearby ground. Above: $\mathrm{N}-\mathrm{S}$ direction; below : $\mathrm{E}-\mathrm{W}$ direction.

from the building into the ground through the basement walls, but it is thought that most of the energy was transferred through the foundation into the ground beneath it, with the backfill on the sides playing a minor role in the interaction.

From the records taken during these tests it was found that the horizontal motion of the nearby ground was always in phase with the building motion in the translational modes. This is consistent with the frequencies of excitation used, which at a wave velocity typical of the type of soil at the site imply a half-wave length of motion in the soil exceeding considerably the distances involved in the tests. The phasing of the vertical motions is indicated by the arrows in Figures 6 and 9 which show that the ground surface was always in phase with the rocking of the building foundation.

It was during these foundation interaction tests that it was observed that the wave motions originating at the Library were being recorded approximately three miles away at the Caltech Seismological Laboratory. Additional measurements of these distant motions were made and a report is in preparation. 


\section{Discussion and Conclusions}

The following conclusions regarding the dynamics of the Millikan Library building can be drawn from the test results. It is expected that these conclusions would be valid also for similar buildings founded on firm soil.

(1) The building showed nonlinear stiffness properties characteristic of a softening dynamic system. The decrease in resonant frequency with amplitude was almost linear over the range of testing (see Figure 7); a more nearly linear decrease was found in similar tests of a five-story reinforced concrete building (Nielsen, 1964). However, it is important to note that the nonlinearities in resonant frequency are small, about 3 per cent over the test range, so periods determined from low-level vibration tests will suffice for most purposes. The fundamental periods of this reinforced concrete shear-wall building were shorter than those for typical open-frame buildings of the same height, indicating that it has a relatively high rigidity.

(2) The mode shapes for oscillations in the N-S (Figure 6), E-W (Figure 9) and torsional fundamental modes remained essentially unchanged with changes in amplitude. Thus, with minor exceptions, the nonlinearities that

- typified resonant frequency and damping measurements were not reflected in changing mode shapes.

(3) From the data defining the foundation motion of the building during vibration in the fundamental modes it is concluded that the structure behaved essentially as if it were fixed at the foundation, rather than at ground level. The measured rocking motion, although inducing easily measurable soil motions, contributed a negligible amount to the total response of the building.

(4) From the preliminary tests it is concluded that the floor systems of the structure are effective as rigid diaphragms.

(5) The precast concrete window panels add only mass to vibrations in the N-S direction, but contribute both mass and stiffness to E-W motions. Therefore, in analyzing $\mathrm{E}-\mathrm{W}$ vibrations these panels must be considered as structural elements.

Energy dissipation by the structure varied markedly with amplitude and conclusions are difficult to make. As measured by an equivalent damping factor the dissipation varied from about 0.6 per cent in the man-excited tests to a maximum of nearly 2 per cent in the largest amplitude forced vibration test. This is a large change over an amplitude range with a maximum only about one tenth what might be expected in a strong earthquake. Also, the energy dissipation picture is complicated by the type of results shown in tests $8 \mathrm{a}$ and $8 \mathrm{~b}$ which show the dissipation to be sensitive to test history as well as amplitude. Similar complications were found in previous tests (Nielsen, 1964; Hansen, 1965a). These results show that it is not feasible to predict from these tests what the energy dissipation will be at amplitude levels expected in strong earthquakes. Clearly what is needed are tests at higher stress levels, both under controlled laboratory conditions and in the field by recording earthquake response. For example, in the event of a strong earthquake near the library site, the recorded acceleration at the roof and at the foundation, coupled with the dynamic properties of the building found from the vibration tests, should 
enable a reasonable estimate to be made of the energy dissipation of this structure at amplitudes typifying earthquake response.

In the equivalent damping factors given in Tables 2,4 and 6 it is seen that the values from method III always exceed those from methods I and II which generally tend to agree with each other. Because all methods use the same resonant amplitude, the discrepancy may lie in the value of the minimum response acceleration being larger than assumed in the development of the method.

The soil-structure interaction data indicate that although the effects of interaction on the building dynamics may be small, it is possible to excite measurable ground motion at appreciable distances from the structure. Thus, the results given here show it is possible to perform full-scale interaction tests as a needed accompaniment to the theoretical work in this field.

\section{ACKNOWLEDGMENT}

The authors are grateful for the assistance and encouragement given by R. A. Matthiesen, D. E. Hudson and R. F. Scott.

Appreciation is extended also to the National Science Foundation for partial support of this study under NSF Grant 1197X.

\section{REFERENCES}

Bouwkamp, J. G. and J. K. Blohm (1966). Dynamic response of a two-story steel frame structure, Bull. Seism. Soc. of Am. 56, 1289-1303.

Converse Foundation Engineers (1959). Foundation Investigation, Proposed Library Building, California Institute of Technology. Project No. 59-110-A.

Englekirk, R. E. and R. B. Matthiesen (1967). Forced vibration of an eight-story reinforced concrete building, Bull. Seism. Soc. of Am. 57, 421-436.

Hanson, R. D. (1965a). Post Elastic Dynamic Response of Mild Steel Structures, Earthquake Engr. Res. Lab., Calif. Inst. of Tech., Pasadena.

Hanson, R. D. (1965b). Static and Dynamic Tests of a Full Scale Steel Frame Structure, Earthquake Engr. Res. Lab., Calif. Inst. of Tech., Pasadena.

Hisada, T. and K. Nakagawa (1956). Vibration Tests on Various Types of Buildings up to Failure, Proc. 1st World Conf. on Earthquake Engr., Berkeley.

Housner, G. W. (1957). Interaction of building and ground during an earthquake, Bull. Seism. Soc. of Am. 47, 179-186.

Hudson, D. E. (1962). Synchronized Vibration Generators for Dynamic Tests of Full Scale Structures, Earthquake Engr. Res. Lab., Calif. Inst. of Tech., Pasadena.

Hudson, D. E., W. O. Keightley and N. N. Nielsen (1964). New method for measurement of natural periods of buildings, Bull. Seis. Soc. of Am. 54, 233-241.

Kawasumi, K. and K. Kanai, (1956). Small amplitude vibration of actual buildings, Proc. 1st World Conf. on Earthquake Engr., Berkeley.

Keightley, W. O., G. W. Housner and D. E. Hudson (1961). Vibration Test of the Encino Dam Intake Tower, Earthquake Engr. Res. Lab., Calif. Inst. of Tech., Pasadena.

Keightley, W. O. (1963). Vibration Test of Structures, Earthquake Engr. Res. Lab., Calif. Inst. of Tech., Pasadena.

Keightley, W. O. (1964). A Dynamic Investigation of Bouquet Canyon Dam, Earthquake Engr. Res. Lab., Calif. Inst. of Tech., Pasadena.

Kuroiwa, J. H. (1967). Vibration Test of a Multistory Building, Earthquake Engr. Res. Lab., Calif. Inst. of Tech., Pasadena.

Matthiesen, R. B. and C. B. Smith (1966). A Simulation of Earthquake Effects on the UCLA Reactor Using Structural Vibrations, Department of Engr., Univ. of Calif., Los Angeles.

Merrit, R. G. and G. W. Housner (1954). Effect of foundation compliance on earthquake stresses in multistory buildings, Bull. Seism. Soc. Am. 44, 551-569.

Nakagawa, K. (1960). Vibrational characteristics of buildings, Part II-vibrational character- 
istics of reinforced concrete buildings existing in Japan, Proc. 2nd World Conf. on Earth quake Engr., Tokyo.

Nielsen, N. N. (1964). Dynamic Response of Multistory Buildings, Earthquake Engr. Res. Lab., Calif. Inst. of Tech., Pasadena.

Parmelee, R. A. (1967). Building foundation interaction effects, J. Engr. Mech. Div., ASCE, No. EM2, Proc. Paper 5200.

Penzien, J. and A. K. Chopra (1965). Earthquake response of appendage on a multistory building, Proc. Brd World Conf. on Earthquake Engr., Wellington.

Skinner, R. I., Skilton, D. W. and D. A. Laws (1965). Unbalanced buildings and buildings with light towers, under earthquake forces, Proc. 3rd World Conf. on Earthquake Engr., Wellington.

Takeucki, M. (1960). Vibrational charaeteristics of buildings, Part I--vibrational characteristics of actual buildings determined by actual tests, Proc. 2nd World Conf. on Earthquake Engr., Tokyo.

Division of Engineering and Applied Sorence

California Institute of Technology

Pasadena, California 91109

Manuseript received September 22, 1967. 